\title{
L'Europe et le monde germanique(époque moderne et contemporaine)
}

Jacques Le Rider

\section{OpenEdition}

\section{Journals}

Édition électronique

URL : https://journals.openedition.org/ashp/1349

DOI : 10.4000/ashp.1349

ISSN : 1969-6310

Éditeur

Publications de l'École Pratique des Hautes Études

\section{Édition imprimée}

Date de publication : 1 octobre 2012

Pagination : 263-264

ISSN : 0766-0677

\section{Référence électronique}

Jacques Le Rider, «L'Europe et le monde germanique(époque moderne et contemporaine) », Annuaire de l'École pratique des hautes études (EPHE), Section des sciences historiques et philologiques [En ligne], 143 | 2012, mis en ligne le 26 septembre 2012, consulté le 03 août 2021. URL : http:// journals.openedition.org/ashp/1349; DOI : https://doi.org/10.4000/ashp.1349 


\title{
L'EUROPE ET LE MONDE GERMANIQUE (ÉPOQUE MODERNE ET CONTEMPORAINE)
}

\author{
Directeur d'études : M. Jacques LE RIDER
}

Programme de l'année 2010-2011 : I. Fritz Mauthner (1849-1923) et le "scepticisme linguistique ». - II. Présences juives dans la culture viennoise (1880-1938) [suite].

Le « tournant linguistique » de Fritz Mauthner répond à quelques motivations existentielles, conditionnées par sa biographie et sa situation historique. Mauthner s'est senti privé de langue et de religion maternelles (il parle dans ses Souvenirs de Mutterreligion, mot formé sur le modèle de Muttersprache). Il considéra que la pluralité culturelle et linguistique (allemand, tchèque, hébreu, yiddish, sans compter les parlers mélangés) dans laquelle il avait passé son enfance et sa jeunesse avait entravé sa formation et sa socialisation. Cette interprétation de Mauthner par lui-même est suggérée dans les écrits autobiographiques publiés à partir de 1910 et rassemblés en 1918 dans le volume de Souvenirs (Erinnerungen). Il reprend cette interprétation dans la " Présentation par lui-même » (Selbstdarstellung) de 1922 et dans l'essai posthume à base autobiographique publié en traduction anglaise en 1924, "Scepticism and the Jews » Après avoir cédé au nationalisme linguistique, dans Le dernier Allemand de Blatna (1887), qui exprime l'angoisse d'un Allemand face à ce qu'il se représente comme un raz-de-marée tchèque menaçant les îlots germanophones de Bohême, puis dans Le manuscrit de Bohême (1897), qui pousse la satire des Tchèques jusqu'à la caricature, Mauthner parvient en 1920 à une conception moins crispée du rôle identitaire des langues nationales et de la pluralité linguistique en Europe centrale, dans la brochure Muttersprache und Vaterland (Langue maternelle et patrie).

Ayant choisi de s'installer à Berlin en 1876, de préférence à Vienne, la capitale de la monarchie habsbourgeoise multiculturelle, Mauthner subit à partir de 1879 le choc de la controverse berlinoise sur l'antisémitisme : son scepticisme linguistique, à partir des Contributions à une critique du langage (1901-1902), est l'aboutissement de deux décennies de doute et de désillusion. La critique du langage a pour visée la critique de la culture.

Il est devenu habituel de parler d'une tradition autrichienne de la philosophie et de renouer avec l'exposé historique d'Otto Neurath, Le Développement du Cercle de Vienne et l'avenir de l'empirisme logique, de 1935. On évoque la tradition autrichienne de la philosophie analytique et du tournant sémantique dont les jalons sont Bolzano, Brentano, Wittgenstein, le Cercle de Vienne et à laquelle on peut rattacher Fritz Mauthner. Cette tradition se caractérise en particulier par l'importance prise par la pensée du « réaliste rigoureux » Johann Friedrich Herbart (1776-1841) à partir de 1849. Plusieurs chaires de philosophie des universités de la monarchie habsbourgeoise furent occupées par des herbartiens déclarés qui présidèrent à la rédaction des manuels scolaires utilisés dans les classes de propédeutique philosophique des lycées. Récusant 
à la fois l'idéalisme et l'empirisme, refusant le transcendantal kantien et cherchant à proposer une autre théorie de la production des représentations, Herbart fait de la langue une force autonome. Il considère la psychologie comme la seule science habilitée à l'approche analytique des structures du sujet. La grammaire raisonnée est pour Herbart un domaine central de la psychologie cognitive. Les vues de Mauthner sur le langage s'inscrivent dans cette tradition herbartienne, renouvelée par Heymann Steinthal qui est une des références centrales de Mauthner de la Critique du langage de 1901-1902 et dans Le Langage de 1907.

Une autre composante de la tradition autrichienne de la philosophie est l'épistémologie du physicien Ernst Mach qui défendait un point de vue strictement empiriste. Mach fut professeur de physique expérimentale au Polytechnikum, préfiguration d'une Université technique intégrée à l'université de Prague, de 1867 à 1895. Mauthner, qui écouta les conférences publiques de Mach à Prague, prend modèle sur l'orientation antimétaphysique de Mach.

En 1872 Mauthner découvre La quadruple racine du principe de raison suffisante, de Schopenhauer, et en 1874, la Deuxième Considération inactuelle de Nietzsche, De l'utilité et de l'inconvénient de l'histoire pour la vie. Si l'on peut dire que, sur quelques points importants, sa critique du langage se rattache à la tradition autrichienne de la philosophie analytique, le scepticisme linguistique de Mauthner est aussi et surtout d'inspiration schopenhauerienne et nietzschéenne.

Les principales références de Mauthner en matière de théorie du langage sont celles de la Bildung classique, fondée sur le néohumanisme de Goethe et de Humboldt. Il tire Humboldt en direction d'une conception de la langue comme forme contraignante de la pensée. Pour éviter que son scepticisme linguistique retombe dans le nihilisme, Mauthner s'approprie enfin la tradition de la mystique allemande du logos. Mais sa lecture athée de Maître Eckhart ne retient que la critique de langue humaine et l'éloge du silence pour aboutir à ce que Gustav Landauer, commentant Mauthner, appelle une « mystique sans Dieu ».

Les dernières séances de l'année 2010-2011 ont permis d'aborder l'autre point du programme : les présences juives dans la culture viennoise (1880-1938). C'est sur ce sujet que portera la conférence 2011-2012. 